\title{
Typical Rett Syndrome in a young boy with hemizygous C.316C > T mutation in MECP2 gene
}

\author{
Murat Coskun ${ }^{\circledR}$, Seda Erbilgin ${ }^{2}$, Ibrahim Akalin ${ }^{3 \oplus}$, Ilyas Kaya ${ }^{\circledR}$, Zeynep Nur Gulle $^{1 \oplus}$, Afig Berdeli ${ }^{4}$ \\ ${ }^{1}$ Istanbul University, Istanbul Faculty of Medicine, Department of Child and Adolescent Psychiatry, Istanbul - Turkey \\ ${ }^{2}$ Istanbul Okmeydanı Training and Research Hospital, Department of Child and Adolescent Psychiatry, Istanbul - Turkey \\ ${ }^{3}$ Istanbul Medeniyet University, Faculty of Medicine, Department of Medical Genetics, Istanbul - Turkey \\ ${ }^{4}$ Ege University, Faculty of Medicine, Department of Pediatric Rheumatology, Izmir - Turkey
}

\begin{abstract}
Mutations in the Methyl-CpG-binding protein 2 (MECP2) gene have been implicated in the etiology of Rett syndrome (RTT), a neurodevelopmental disorder that primarily affects girls. MECP2 mutations in males, once thought to be lethal, are now recognized with a broad spectrum of clinical manifestations. Here we report a 3-year-old boy who presented with developmental problems and regression and eventually was diagnosed with RTT that genetic analysis revealed to be a hemizygous C.316C>T missense mutation in the MECP2 gene suggesting somatic mosaicism with the normal 46,XY karyotype. DNA analysis of the patient's mother showed this either to be a de novo mutation or a case of gonadal mosaicism. To the best of our knowledge, this is the first case report of RTT in a young boy with a hemizygous C.316C>T mutation in the MECP2 gene.
\end{abstract}

Keywords: c.316C>T, male, MECP2 mutation, rett syndrome, somatic mosaicism

\section{INTRODUCTION}

Rett Syndrome (RTT, MIM 312750) is an X-linked neurodevelopmental disorder characterized by loss of spoken language and volitional hand use with the development of repetitive hand stereotypes that occur after an apparently normal initial six to eighteen months of development (1). RTT is almost exclusively seen in girls (1) and rarely reported in male patients (2-8). In 1999, Amir et al. (9) discovered that mutations in the gene encoding Methyl-CpG-binding protein 2 (MECP2) were associated with the most common sporadic occurrences of typical RTT in addition to rare familial cases. Mutations in MECP2 can be detected in 95-97\% of subjects with typical RTT, while a lower rate of mutations, 50-70\%, has been reported in atypical cases (1). Although the precise function of MECP2 has not been fully understood, dysfunction or loss of MECP2, as observed in RTT, would be predicted to give rise to inappropriate activation of genes (10).

Typically, affected girls follow an apparently normal development during the first months of life. Between six months and two years of age, developmental regression becomes evident through the loss of speech, purposeful hand movements, and social as well as cognitive abilities (1). In the past, MECP2 mutations in male patients have been thought to be lethal. However, today, it is supposed to present with a broad spectrum of clinical manifestations from death in infancy to developmental delay associated with seizures and

How to cite this article: Coskun M, Erbilgin S, Akalin I, Kaya I, Gulle ZN, Berdeli A. Typical Rett Syndrome in a young boy with hemizygous c.316C>T mutation in MECP2 gene. Dusunen Adam The Journal of Psychiatry and Neurological Sciences 2020;33:99-103.

Correspondence: Zeynep Nur Gulle, Department of Child and Adolescent Psychiatry, Istanbul Faculty of Medicine, Istanbul University, Istanbul 34390, Turkey

Phone: +90 5386259060 - 2124142023 E-mail: zeynepnur.gulle@gmail.com

Received: May 02, 2019; Revised: August 03, 2019; Accepted: November 21, 2019 
neurological disorders, as well as non-specific mental retardation $(2-8,11,12)$. In this study, we report a 40-month-old boy who was initially diagnosed with autism at 24 months and then received the diagnosis of RTT in the 32nd month with a typical hemizygous c. 316C $>$ T mutation in MECP2 gene.

\section{CASE}

\section{Clinical Presentation}

A 24-month-old boy was referred to our hospital by his parents with a number of developmental problems and abnormal behaviors. His psychiatric examination revealed significant deficits in language and social developments, as well as several stereotypic hand movements. Despite of some level of vocalization, he almost had no meaningful words and could not understand short simple comments. Although he used to have some level of eye contact or social responsiveness in his domestic environment with family members, he made no eye contact and did not respond to his name during clinical examination. He showed almost no meaningful play or imitations. Stereotypic behaviors, such as hand clapping and wringing, were observed. He was able to walk without support. He was given a DSMIV diagnosis of autistic disorder and referred to a special psycho-educational rehabilitation program. Laboratory workup, including inborn errors of metabolism, brain imagining, electroencephalography (EEG), and brain auditory evoked response test (BAER), were unremarkable. His parents gave verbal informed consent for the study.

\section{Developmental History}

The patient is the first child of healthy unrelated parents. He was born at term with normal spontaneous vaginal delivery after an uneventful pregnancy. His birth weight was $3200 \mathrm{~g}$ (50 percentile), birth height was $50 \mathrm{~cm}$ (50 percentile), and his head circumference was $34 \mathrm{~cm}$ ( 25 percentile). The patient's developmental milestones included head control at the age of three months, sitting with support at the age of six months, sitting without support at the age of nine months, walking with support at the age of 12 months, and walking without support at the age of 18 months. $\mathrm{He}$ started to vocalize at the age of 10 months but he has acquired almost no meaningful words so far. Review of home videos revealed that, at the age of 12 months, he had developed stereotypical behaviors, such as swinging and hand clapping, and limited social responsiveness. At the age of 20 months, stereotypes such as hand wringing and washing movements started and his purposeful use of hands and fingers began to deteriorate. He has had severe bruxism since the age of one year. His family history revealed that he has a maternal cousin with autism. No other family members had neurological diseases.

Although he attended a special education program regularly, his motor and social skills deteriorated and his stereotypic behaviors increased over time. At age 30 months, he started to show truncal ataxia and gait apraxia, and he was not able to stand up without support. His fine motor skills, such as holding a spoon in his hand, regressed. He was reported to have no eye contact or social responsiveness in the domestic environment anymore. His vocalization and bubbling also disappeared. We observed intense midline stereotypes such as hand washing and hand-to-mouth movements at the age of 30 months. He was almost always performing these midline stereotypic behaviors and it was difficult to stop this behavior with any distracters. His physical examination revealed scoliosis and mild microcephaly with a head circumference of $48 \mathrm{~cm}$ at 30 months of age (18 percentile). Given his clinical picture, including deterioration in social and motor skills, developing intense midline stereotypic behaviors and scoliosis, a provisional diagnosis of RTT was considered. We ordered MECP2 gene mutation analysis.

\section{Genetic Analysis}

Genetic analysis was conducted for the subject and his mother using peripheral venous blood. Cytogenetic analysis of the boy revealed normal 46,XY karyotype. Molecular analyses using the MLPA (Multiplex Ligation-dependent Probe Amplification) (PO15MECP2/Lot 0909) method did not reveal any deletion or duplication in 28 regions including MECP2, NTNG1, CDKL5, ARX, SLC6A8, L1CAM, FLNA, GDI1, and DKC1 genes. However, MECP2 (NM_004992.3, NP_004983.1) gene sequence analysis revealed a c.316C>T (rs28934907, p.R106W) hemizygous point mutation at exon three (Applied Biosystems 3130xl Genetic Analyzer, Foster City, California 94404, USA) (Figure 1). No genetic abnormality was detected in the mother (Figure 2).

After molecular genetic confirmation of RTT, the patient was followed until the age of 46 months. While he did not have clinical seizures, his sleep-deprived EEG showed diffuse slow-wave activity. Valproat $200 \mathrm{mg} /$ day was started by the neurologist. The patient's head circumference was $48 \mathrm{~cm}$ at 36 months of age (10 

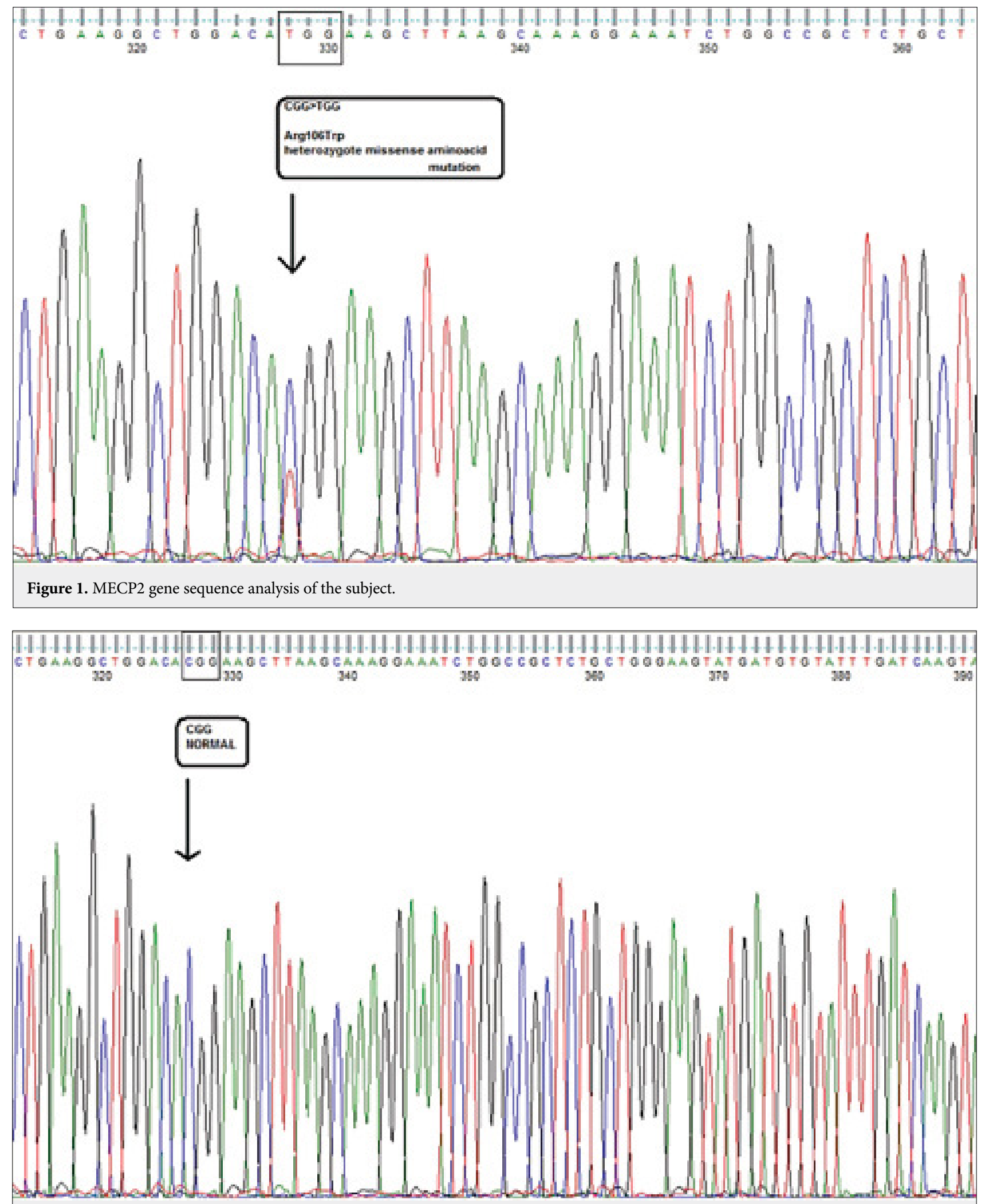

Figure 2. MECP2 gene sequence of the mother.

percentile) and at 46 months of age (below the 10 percentile). At 44 months of age, he started to have occasional breath-holding spells. His problems with gait, motor skills, stereotype behaviors, and social deficits continued with no significant change. Although his control sleep EEG was abnormal, his medication 
was discontinued by the family as he had no clinical seizures.

\section{DISCUSSION}

Typical RTT with mutation in the MECP2 gene has rarely been reported in male subjects. Here we presented a male patient diagnosed with Rett Syndrome with a c.316C > T (rs28934907, p.R106W) hemizygous point mutation at exon 3 of the MECP2 gene suggesting somatic mosaicism.

While males do not develop typical Rett Syndrome unless they have a $47, \mathrm{XXY}$ karyotype or somatic mosaicism, our patient revealed a clear 46,XY chromosomal constitution. Additionally, somatic mosaicism has been documented in male patients with MECP2 mutations associated with classical RTT $(6,7)$. Therefore, we assumed our patient to be a case of somatic mosaicism for a c.316C $>$ T mutation.

The identified mutation (p.R106W) is diseasecausing since it is a missense mutation. The R106W mutation, being in a highly conservative methyl-CpGbinding domain of $\mathrm{MeCP} 2$, has been detected in other female patients with classical RTT (9). In-vitro studies have demonstrated that the R106W mutation within the methyl-binding domain leads to substantial deterioration of $\mathrm{MeCP} 2$ functions by weakening its selectivity for methylated DNA $(13,14)$. The mutation, when transfected into cells, leads to impairment of its ability to localize to heterochromatins and in consequence to repression of transcription.

The clinical picture in male patients with confirmed MECP2 gene mutation is characterized by variable degrees of severity ranging from severe encephalopathy and early death to severe mental retardation and autistic pictures (1). In addition to typical RTT, it has been recognized that some individuals present with many of the clinical features of RTT, such as regression, but do not necessarily have all of the features of the disorder. These have been termed "variant" or "atypical" RTT (1). A literature review found several papers reporting typical or atypical Rett syndrome in male subjects with R133C (5), S134C (2), c.1158del44 or p.388X (3), c.360T $>$ G or Y120X (6), $808 \mathrm{C}>\mathrm{T}$ or R270X (7), T158M (4), and 754insC or E250X (8) mutations in the MECP2 gene. The present living case is one of the few that had typical features of Rett syndrome, where a disease-causing hemizygous c.316C $>\mathrm{T}$ (rs28934907, p.R106W) missense mutation at the MECP2 gene might represent somatic mosaicism. Moreover, given that the MEPC2 mutations were dominant in character, the absence of a c.316C $>\mathrm{T}$ mutation in the mother indicated the mutation to be de novo in the patient or the presence of gonadal mosaicism in the mother (15).

Neul et al. (1) reviewed the recent diagnostic criteria and nomenclature of RTT. The possibility of RTT should be considered when postnatal deceleration of head growth is observed. Our case met all the diagnostic and exclusion criteria for typical RTT. For typical or classical RTT, in addition to a period of regression followed by recovery or stabilization, 4 main criteria should be present 1) Partial or complete loss of acquired purposeful hand skills (e.g., inability to hold a spoon), 2) Partial or complete loss of acquired spoken language (i.e. the loss of vocalization and bubbling), 3) Gait abnormalities: impaired (dyspraxic) or absence of ability (i.e. unstable and ataxic gait, inability to stand up without support), 4) Stereotypic hand movements such as hand wringing/ squeezing, clapping/tapping, mouthing and washing/ rubbing automatisms (incl. intense hand washing and hand to mouth movements). Two main exclusion criteria for typical RTT were also met: 1) brain injury secondary to trauma and neurometabolic disease or severe infection causing neurological problems (i.e., no significant history of trauma or neurological disorders) 2) grossly abnormal psychomotor development in the first 6 months of life (such as head control at 3 months of age, sitting with support at the age of 6 months, sitting without support at the age of 9 months, walking with support at the age of 12 months, and walking without support at the age of 18 months). Although supportive criteria are not required for a diagnosis of typical RTT, he also met several supportive criteria such as scoliosis, severe bruxism, and breath-holding spells.

The subject was initially diagnosed with autistic disorder at 24 months of age. Later on, he showed deterioration in language, social and motor skills alongside with typical midline/mouthing stereotypic movements leading to suspicion of Rett syndrome. MECP2 gene mutation analyses was requested and we found a hemizygous c.316C $>\mathrm{T}$ (rs28934907, p.R106W) mutation at exon three.

This case report may highlight that Rett syndrome should be considered in female and male subjects with a diagnosis of pervasive developmental disorder and genetic analysis should be recommended if they show developmental deterioration over time. Here, for the first time we reported a male subject with hemizygous c. $316 \mathrm{C}>\mathrm{T}$ mutation in the MECP2 gene representing 
clinical features of typical Rett syndrome, suggesting somatic mosaicism.

\begin{tabular}{|l|l|l|}
\hline \multicolumn{4}{|l|}{ Contribution Categories } & Author Initials \\
\hline \multirow{4}{*}{ Category 1} & Concept/Design & M.C., I.K. \\
\cline { 2 - 3 } & Literature review & S.E. \\
\cline { 2 - 3 } & Data analysis/Interpretation & I.A., A.B. \\
\cline { 2 - 3 } & Case follow-up (if applicable) & I.A., A.B., S.E. \\
\hline \multirow{3}{*}{ Category 2} & Drafting manuscript & M.C., Z.N.G., S.E. \\
\cline { 2 - 3 } & Critical revision of manuscript & I.A., A.B. \\
\hline Category 3 & Final approval and accountability & M.C. \\
\hline \multirow{2}{*}{ Other } & Technical or material support & M.C., I.A. \\
\cline { 2 - 3 } & Supervision & N/A \\
\hline
\end{tabular}

Informed Consent: Parents gave verbal informed consent for publication.

Peer-review: Externally peer-reviewed.

Conflict of Interest: The authors declare that there is no conflict of interest regarding the publication of this article.

Financial Disclosure: The authors declare that there is no financial support regarding the publication of this article.

\section{REFERENCES}

1. Neul JL, Kaufmann WE, Glaze DG, Christodoulou J, Clarke AJ, Bahi-Buisson N, et al; RettSearch Consortium. Rett syndrome: revised diagnostic criteria and nomenclature. Ann Neurol 2010; 68:944-950. [CrossRef]

2. Budden SS, Dorsey HC, Steiner RD. Clinical profile of a male with Rett syndrome. Brain Dev 2005; 27(Suppl 1):S69-S71. [CrossRef]

3. Dayer AG, Bottani A, Bouchardy I, Fluss J, Antonarakis SE, Haenggeli CA, et al. MECP2 mutant allele in a boy with Rett syndrome and his unaffected heterozygous mother. Brain Dev 2007; 29:47-50. [CrossRef]

4. Leonard H, Silberstein J, Falk R, Houwink-Manville I, Ellaway C, Raffaele LS, et al. Occurrence of Rett syndrome in boys. J Child Neurol 2001; 16:333-338. [CrossRef]
5. Masuyama T, Matsuo M, Jing JJ, Tabara Y, Kitsuki K, Yamagata $\mathrm{H}$, et al. Classic Rett syndrome in a boy with R133C mutation of MECP2. Brain Dev 2005; 27:439-442. [CrossRef]

6. Pieras JI, Munoz-Cabello B, Borrego S, Marcos I, Sanchez J, Madruga M, et al. Somatic mosaicism for Y120X mutation in the MECP2 gene causes atypical Rett syndrome in a male. Brain Dev 2011; 33:608-611. [CrossRef]

7. Topcu M, Akyerli C, Sayi A, Toruner GA, Kocoglu SR, Cimbis M, et al. Somatic mosaicism for a MECP2 mutation associated with classic Rett syndrome in a boy. Eur J Hum Genet 2002; 10:77-81.

8. Zeev BB, Yaron Y, Schanen NC, Wolf H, Brandt N, Ginot N, et al. Rett syndrome: clinical manifestations in males with MECP2 mutations. J Child Neurol 2002; 17:20-24. [CrossRef]

9. Amir RE, Van den Veyver IB, Wan M, Tran CQ, Francke U, Zoghbi HY. Rett syndrome is caused by mutations in X-linked MECP2, encoding methyl-CpG-binding protein 2. Nat Genet 1999; 23:185-188. [CrossRef]

10. Nussbaum RL, McInnes RR, Willard HF (editors). Thompson \& Thompson Genetics in Medicine. Seventh Ed. Philadelphia: Saunders Elsevier, 2007. [CrossRef]

11. Campos M Jr, Abdalla CB, dos Santos AV, Pestana CP, dos Santos JM, Santos-Reboucas CB, et al. A MECP2 mutation in a highly conserved aminoacid causing mental retardation in a male. Brain Dev 2009; 31:176-178. [CrossRef]

12. Campos M Jr, Pestana CP, dos Santos AV, Ponchel F, Churchman $\mathrm{S}$, Abdalla-Carvalho $\mathrm{CB}$, et al. A MECP2 missense mutation within the MBD domain in a Brazilian male with autistic disorder. Brain Dev 2011; 33:807-809. [CrossRef]

13. Kudo S, Nomura Y, Segawa M, Fujita N, Nakao M, Dragich J, et al. Functional analyses of $\mathrm{MeCP} 2$ mutations associated with Rett syndrome using transient expression systems. Brain Dev 2001; 23 (Suppl 1):S165-173. [CrossRef]

14. Yusufzai TM, Woffle AP. Functional consequences of Rett syndrome mutations on human MeCP2. Nucleic Acids Res 2000; 28: 4172-4179. [CrossRef]

15. Akalin I, Yararbas K, Akgul N, Babaoglu E, Akay GG, Dyer $\mathrm{S}$, et al. del5p/dup5q in a 'cri du chat' patient without parental chromosomal rearrangement. Am J Med Genet A 2006; 140:10161020. [CrossRef] 